\title{
Adolescent Health in India: Still at Crossroads
}

\author{
Mona Gupta ${ }^{1}$, K. V. Ramani ${ }^{2}$, Werner Soors ${ }^{3}$ \\ ${ }^{1}$ MSG Strategic Consulting, New Delhi, India \\ ${ }^{2}$ Indian Institute of Management, Ahmedabad, India \\ ${ }^{3}$ Prince Leopold Institute of Tropical Medicine, Antwerp, Belgium \\ Email: mona.hrd@gmail.com; ramani@iimahd.ernet.in; wsoors@itg.be
}

Received August 16 $6^{\text {th }}$, 2012; revised September $18^{\text {th }}$, 2012; accepted September $30^{\text {th }}, 2012$

\begin{abstract}
Internationally, Adolescent Reproductive and Sexual Health (ARSH) has become a priority programme approach to help the future generations have a safe, healthy and satisfactory life. India is yet to develop a comprehensive policy on ARSH mainly due to lack of inter-ministerial collaboration, socio-cultural and politico-religious factors, even though evidence from surveys and non- governmental organization projects has corroborated the case for ARSH since late 1980s. Fortunately, recent evidence provided by Sample Registration Survey (SRS) 1999, Census 2001, National Family Health Survey (NFHS)-II and District Level Household Survey (DLHS) 2004 particularly on early marriage, teen pregnancy, anaemia and unmet need for contraception has led GoI to recognize the importance of adolescent health. However, a comprehensive ARSH policy is yet to emerge, since components of adolescent health are being addressed by separate ministries and departments. Adolescent health in India is still in an infant stage and at the risk of infanticide. From "health for the adolescents" to "health with the adolescents", it is still a long way to go.
\end{abstract}

Keywords: Adolescents; Reproductive and Sexual Health; Policy; Qualitative Study; Intersectoral Coordination; India

\section{Introduction}

Adolescents have always remained in a dilemma, as they are neither considered children nor adults. A similar fate seems to follow the development of a comprehensive policy on Adolescent Reproductive and Sexual Health (ARSH) in India mainly due to lack of inter-ministerial collaboration, socio-cultural and politico-religious factors. India has about 230 million adolescents in the age group 10 - 19 years, with females comprising about $47 \%$ of the total adolescent population (GoI, 2001). It is this adolescent population which will enter the workforce in the next 5 - 15 years, and play a vital role in India's socio-economic development.

Internationally, $\mathrm{ARSH}^{1}$ has become a priority programme approach to help the future generations have a safe, healthy and satisfactory life. In this paper $^{2}$, we briefly trace the history of ARSH in India to understand its present situation and deliberate on problems coming in way of a comprehensive ARSH policy. It builds upon research undertaken on ARSH in India throughout the HEPVIC (Health Policy-making in Vietnam, India and China) project between 2006 and 2009. This research project ${ }^{3}$

\footnotetext{
${ }^{1}$ Internationally, Adolescent Sexual and Reproductive Health (ASRH) is a more widely accepted term. In a rights-based perspective, "sexual health" is more comprehensive and thus precedes "reproductive health". In India however, Adolescent Reproductive and Sexual Health (ARSH) was used for a long time. Since 2011, GoI has started using the term adolescent health which includes ARSH, school health, menstrual hygiene and others.

${ }^{2}$ This paper briefs on core findings from the study done in India on ARSH as a part of the HEPVIC (Health Policy-making in Vietnam, India and China) research project supported by the European Community Sixth Framework Programme (INCO-CT-2005-517746).

${ }^{3}$ The HEPVIC project involved a consortium of eight partners: University of Leeds, UK (coordinator); Hanoi School of Public Health, Vietnam; Indian Institute of Management Ahmedabad (IIMA), India; Fudan University, China; Liverpool School of Tropical Medicine, UK; Prince Leopold Institute of Tropical Medicine (ITM), Belgium; Royal Tropical Institute, Netherlands; and University of Bologna, Italy. This study was carried out by IIMA in association with ITM.
}

explored the nature of health policy process and more specifically how the policy processes used evidence, handled the consideration and integration of different policy aspects, and involved a range of different actors ${ }^{4}$. Three case studies were selected from each country to understand the policy process in maternal health. The case studies in India focused on skilled birth attendance, medical termination of pregnancy (abortion) and ARSH. Within the wider HEPVIC scope, we report here on the Indian case study on ARSH and focus on the contribution (or lack of it) of actors in the policy process ${ }^{5}$.

\footnotetext{
${ }^{4}$ The HEPVIC study conceived policy processes as "the formal and informal mechanisms through which policies are developed (policy development and its subsequent implementation (policy implementation)", and actors as "individuals or institutions who are associated with, and either involved or not involved in, policy processes”.

${ }^{5}$ This study, the main data were collected through in-depth interviews with key stakeholders. Non-random, purposive sampling and snowballing was used to select respondents. Separate open-ended questionnaires were developed for each group of respondents, e.g. government policy-makers and civil society representatives. During the interview, care was taken to ensure that respondents were able to speak freely on topics/issues not covered by the questionnaire but what they thought to be relevant. All interviews were conducted between March 2007 and October 2008. Out of a total of 34 interviews, 9 were exclusively for the ARSH case study. Politicians though very important actor could not be interviewed because of sensitivity issues. All interviews but one were audio recorded with informant's consent and transcribed verbatim. One respondent did not permit recording of the interview so extensive notes were taken. Each interview lasted between 45-120 minutes. Secondary data were obtained from literature. NVivo 7.0 was used as primary aid to organize, index, chart and map the data. After a first round of interviews, triangulation and analysis, preliminary study results were presented in a participatory stakeholder workshop (International Workshop on Maternal Health Policy Process, IIMA, 25-26 October 2007) to allow feedback from the stakeholders. A second round of interviews and analysis concluded in the presentation and discussion of the final study results in another Stakeholders’ Workshop (IIMA, 18 February 2009).
} 


\section{ARSH Policy Process: A Brief History}

In India, evidence from surveys and Non Governmental Organization (NGO) projects has corroborated the case for ARSH since the late $1980 \mathrm{~s}^{6}$. The reports of some of their studies suggest that communities must be involved if gains are to be made in changing the social norms that discourage youth from accessing the reproductive and sexual health information they need (Pande, 2006). Though ARSH at that time had been accepted in many countries as an important intervention, it started getting some attention from the Government of India (GoI) only after the International Conference on Population and Development (ICPD) in 1994. ICPD emphasized the need to focus on the reproductive health needs of adolescents as a separate group (RFSU, 2004).

As a signatory to the ICPD declaration, the Government of India initiated the development of an ARSH policy. While the RCH-I (Reproductive and Child Health) Program (1998-2004) did not make any direct mention of adolescent health needs in the objectives or beneficiaries, NACP II (National AIDS Control Program II, 1999-2006) took the challenge seriously and introduced the School AIDS Education Programme (SAEP) in the 9th and 11th grades on a voluntary basis throughout India. Less explicit mention of adolescents was also because RCH-I was mainly concerned with structures and institutional capacities that would be utilized in RCH-II (2005-2010), where a specific focus on adolescent health was planned (UN 2008). As the overarching National health goals are to attain significant decline in the TFR, MMR, and IMR, and efforts are on to limit the HIV spread, reproductive and sexual health became the entry point of adolescent health also. The RCH-II Program recognized ARSH as one among the four strategies (besides Maternal Health, Child Health, and Family Planning) to reduce MMR, IMR and TFR.

Evidence provided by SRS 1999, Census 2001, NFHS-II and DLHS-RCH 2004 particularly on early marriage, teen pregnancy, anaemia and unmet need for contraception led GoI to recognize the importance of adolescent health. In India, more than $50 \%$ of the illiterate girls get married before they reach the legal age of 18 years (ibid). Nearly 27\% of married female adolescents have reported an unmet need for contraception (MoHFW, 2006). Projections estimated significant increase in adolescent pregnancies and births. In 2000 there were an estimated 20.2 million adolescent pregnancies which was projected to increase in subsequent years (Gupta, 2003). According to National Family Health Survey III (IIPS, 2007), 16\% of women between 15 - 19 years were already mothers or pregnant at the time of the survey. Adolescent mothers are at a higher risk of miscarriages, maternal mortality, and morbidity. If a mother is under the age of 18, her infant's risk of dying in its first year of life is $60 \%$ greater than that of an infant born to a mother older than 19 (UNICEF, 2008). An inter-country consultation on adolescent health and development (South-East Asia region) organized by WHO in collaboration with UNFPA and other UN agencies resulted in setting up Adolescent Friendly Health Centres (AFHC) by the GoI. The experience of AFHCs dis-

\footnotetext{
${ }^{6}$ Organisations like Parivar Seva Sanstha, the International Centre for Research on Women (ICRW) India office, Swaasthaya, the Health Institute for Mother and Child (MAMTA) and Family Health International India started adolescent health projects and provided programmatic evidence, where as Census of India, the three rounds of the National Family Health Survey (NFHS) and the 2006-2007 Youth Surveys provided additional quantitative evidence.
}

cussed in a subsequent workshop brought out the need to go beyond clinical services offered by the Health Ministry. In September 2005, MoHFW organized a national consultation jointly with WHO and UNFPA on RCH-II ARSH strategy. The ARSH strategy thus formulated and stated in the National Program Implementation Plan (NPIP) of the RCH II (MoHFW, 2005a) program advocates the use of existing public system infrastructure for ARSH service delivery, working towards meeting the needs of adolescents, and the need for a delivery strategy looking at different stages of development, needs and problems of adolescents. The RCH-II ARSH strategy was communicated to the states in May 2006 in a Dissemination workshop. However a review of the state RCH plans and expenditure for the year 2008-09 shows that most of the states are yet to implement ARSH in all its districts. Fourteen of the 35 states and UTs had reported nil expenditure for ARSH in 2008-09 (MoHFW, 2009).

\section{Multiple Actors, No Ownership}

In India, components of adolescent health are being looked after by separate ministries and departments. The Ministry of Health and Family Welfare (MoHFW) focuses on delivering adolescent health services. The Adolescent Education Programme (AEP) and sex education come under the Department of Education in the Ministry of Human Resource Development (MoHRD), while its earlier version SAEP was administered by National AIDS Control Organization. The program on nutrition and counselling of adolescent girls-Kishori Shakti Yojana-is being looked after by the Ministry of Women and Child Development (MoWCD) under its Integrated Child Development Scheme (ICDS). The National Youth Policy 2003, of the Ministry of Youth Affairs and Sports (MoYaS) recognises adolescents (15 - 19 years) as distinct from the youth (20 - 35 years age), but its focus on ARSH is limited to advocacy on ARSH and life skills (MoYaS, 2008). Thus each ministry is looking after one component of adolescent health and therefore a comprehensive ARSH policy is yet to emerge.

As a respondent from a national NGO commented:

Every department has its own concern; nobody is concerned about the adolescents as a vulnerable group. MoYaS's target population is youth. Its goals are nationalism, sports and personality development. WCD is more concerned with nutrition and empowerment of women. Ministry of Health is into service delivery. Along with other health concerns Adolescent Reproductive and Sexual Health also features in its long list.

Commenting on its multi-sectoral characteristic and the role of the health sector, a respondent from an UN organization said:

There are domains in ARSH, which can be attended to by so many actors. In addition to the civil society, education department, youth department, social justice department, women and child etcetera need to pitch in. Health sector has limited capacity and efficiency especially in developing world. We have to define the health sector's role in the multi-sectoral framework. While collaborating we should be clear that this is what the health sector can do.

Though collaboration and coordination is essential for ARSH, the process of implementation of the Indian ARSH strategy has not addressed the inter-ministerial coordination satisfactorily. The National Programme Implementation Plan (NPIP) of RCH II says that "Department of Health and Family Welfare will need to steer policy dialogue and partnerships with other departments for inter-sectoral activities” (MoHFW, 2005b). But 
the 11th five-year plan document mentions MoYaS as the nodal ministry for youth and adolescent, though with some reservetions: "The MoYaS is the nodal ministry for development and empowerment of youth and adolescents in the country. MoYaS' role and responsibilities in this context are still not clearly defined, which affects its schemes and programmes in terms of their monitorable deliverables and outcomes on the one hand, and dovetailing them in an integrated framework with programs of other ministries" (Planning Commission, 2007). Among the stakeholders interviewed for this research there is consensus that MoYaS lacks the power to fulfil this nodal role. The MoYaS is not a member in the Mission Steering Group and the Empowered Programme Committee-the highest policy making and steering institution under the National Rural Health Mission (NRHM), which includes ministries such as Health and Family Welfare, Rural Development, Panchayati Raj and $\mathrm{Hu}-$ man Resources Development (GoI, 2005).

Highlighting NRHM as an opportunity to initiate inter-sectoral collaboration in ARSH a senior government officer remarked: "As NRHM is the umbrella programme for all health issues and stresses on inter-sectoral collaboration to achieve its objectives, it may be useful to view ARSH policy development as an important inter-sectoral activity under NRHM.”

But in the third year of NRHM (2008-09), ARSH accounted for only $0.4 \%$ (less than $1 \%$ ) of the total expenditure under $\mathrm{RCH} / \mathrm{NRHM}^{7}$.

Multi-sectoral nature of adolescent health becomes even more complicated because of the non-homogeneity of adolescents as a group. Adolescents could be boys and girls, married and unmarried, with diverse sexual preferences, in-school and out of school, working and unemployed, migrants and those at home, of various castes, cultures, religions and economic strata. Programmes and schemes of most ministries and departments cater to some, but leave out too many.

The parliamentary committee looking into what has been termed the "sex education controversy" has expressed dissatisfaction on the total lack of coordination amongst various agencies in formulating and implementing the Adolescent Education Programme (AEP). The Committee would like the Ministry of HRD to oversee the process of revision of AEP under its supervision, direction and control (ibid). The AEP reaches only the school children, and not the large segment of out-of-school boys and girls ${ }^{8}$. In Gujarat, Mamta-Taruni addresses out-ofschool girls, but leaves out the out-of-school boys. MoYaS caters to rural youth through its Nehru Yuva Kendras, but its focus is more on nationalism and sports and not on ARSH. Many NGOs are trying to cater to the adolescents, but their reach is limited in scope and coverage.

The policies at both federal and state levels either belong to specific sectors like health, education, population, nutrition, HIV/AIDS etc. or the policies address specific population segments like youth, women, and children, and therefore the emphasis on adolescents gets diluted (MAMTA, 2001).

\section{The Context Trap}

Complexity of socio-cultural and politico-religious factors

\footnotetext{
${ }^{7}$ With increased focus the expenditure on Adolescent health has increased to $2.5 \%$ in 2011-12 of the total expenditure under RCH/NRHM.

${ }^{8}$ School dropout rates for girls are $19 \%$ and $66 \%$ in the age groups $11-14$ years and 15 - 19 years respectively (IIPS, 1999). The corresponding statistics for boys are $20 \%$ and $51 \%$ respectively. In addition to school dropouts, an average of $22 \%$ of girls and $7 \%$ of boys in the age group 15 - 19 years never attended school.
}

adds on to the complicated interplay of actors. To start with, the concept of "adolescent" has not been a common one in India, where traditionally childhood has been seen as leading directly to adult life. As one of the respondents voiced, "Problem is more serious for people who are illiterate and their children who do not go to school. When the children turn 13 or 14 years their parents think that they are into adulthood, and they should work. By 18 they must get married”.

An INGO respondent synthesized: "A child suddenly becomes adult after marriage”.

Government services delivery fails to recognize the transition through adolescence, particularly in the case of married teenagers. As an INGO respondent commented "A married adolescent for a provider is quite like an adult, in the adult role. Whether the communication capacity of the client has evolved or not, whether the decision-making capacity of the adolescent client is of adult level or not, the provider is not aware".

Socially, married girls are most vulnerable. Within a patriarchal family structure, women have relatively little power, but young and newly married women are particularly powerless, secluded, and voiceless. As one of the respondents from an INGO who has worked extensively in the field of adolescent health said:

They (married girls) are more at risk. They are less likely to be allowed out of house and so less likely to access services. They have very little decision-making power. They probably don't have much communication with their husbands, nor does any health care provider even worry about them until they have a child. An adolescent married girl is socially isolated and has very little contact with her parental home.

As argued by several of our respondents, there is tremendous societal pressure on girls for marrying early and having a child early. In fact, there are strong pressures on women to prove their fertility as soon as possible after marriage: social acceptance and economic security in the marital home are established largely through fertility, and particularly through the birth of a son (Jejeebhoy, 1998). Adolescent girls have little choice about whom and when to marry, whether or not to have sexual relations, and when to bear children. A proposal that was introduced to reduce the legal age at marriage for boys from 21 years to 18 years probably would have put still more pressure on girls, but has been rejected (UNI, 2009).

In India, the politico-religious context has played a very significant role in determining policy and the content of education to be provided to the youth. While parents articulate a need to provide reproductive and sexual health education to their children, political and religious leaders have tended to decide what is good for the youth. Those who apparently have the least say are the key stakeholders: the adolescents themselves. Adolescents have found it difficult to voice their needs. When it comes to reproductive and sexual needs it becomes all the more difficult: sex is a taboo subject. Even the subdued adolescents' demand seems to be only marginally taken into account in the policy process. As stated by a policy-maker the government does not pay much attention to the adolescents' perspective in formulating ARSH policy:

The formal approval of any government policy (central or state government) requires that the policy draft document is tabled in the parliament (or the state legislature) for debate and discussion, or taken to the cabinet for its approval when the parliament (or the state legislature) is not in session. It is up to the parliamentarians (legislators) to get inputs from their con- 
stituencies and stakeholders for discussions during the deliberations of the policy. Yet, an average youth doesn't even know what the whole youth policy is about. Efforts are made in workshops and seminars to give the adolescents and youth a platform to raise their voice. But such efforts are very few.

At times, lack of attention comes close to plain negation: "Because of the potential political backlash and the whole cultural milieu, I think nobody wants to have any major impetus on it. 'Our youth don't have sex'-this attitude still exists": said a respondent from an INGO working with adolescents. Yet, population-level data (Population Council and IIPS, 2007) reveal that premarital sex among female and male youth is a reality. At the same time, a very marginal percentage of the respondents in the IIPS study is engaged in discussions on sexual and reproductive systems, including pregnancy, with their parents.

Lack of health awareness among adolescents is another issue $^{9}$ which is more widely recognised. One of the government policy-makers, quoting an opinion poll conducted by one of the leading fortnightly magazine, indicated that "There is an utter lack of awareness and knowledge about sex and sexuality, ways to use contraceptive methods among the youth".

But lack of knowledge does not equal lack of demand. As one NGO respondent indicated:

Parents of adolescents would like their children-both boys and girls - to receive reproductive health and sex education. Even the adolescents and youth themselves have voiced their needs for sex education. Further, the youth want to know and learn about sex education from a formal source such as school, or college and taught by a teacher or a health provider. Parents do not feel comfortable talking about sex to their children and therefore prefer that their children receive such information from schools from their teachers.

In spite of the fact that both adolescents and their parents have expressed a need for sex education, and government officials recognizing that adolescents lack awareness about sex and sexuality, efforts to provide sex education through the SAEP came under attack (some termed it as cultural hijack) and were discontinued in several states because of political pressure. A political leader had argued that the attempt to impart sex education is a ploy of the multinational companies that are keen on promoting the sale of condoms and other sex devices. Some religious leaders even argued that "sex education would make adolescents promiscuous”. In a country where Valentine's Day celebrations and vibrating condoms are viewed as capable of unsettling the nation, there is no novelty in these arguments. One is only too familiar with them. But their efficacy in stalling sex education in schools is a matter for worry (Anandhi, 2007).

The report from the Rajya Sabha committee on petitions (Rajya Sabha, 2009) officializes the plea for scaling down sex education. The committee appears satisfied with the revision of the AEP by a commission led by the chairman of the Central Board of Secondary Education. But it also advises that chapters like "Physical and Mental Development in Adolescents" and

\footnotetext{
${ }^{9}$ The recently conducted Youth Surveys in six 6 states (Jharkhand, Bihar, Rajasthan, Maharashtra, Andhra Pradesh and Tamil Nadu) show that only less than 1 in $5 \%$ of youth is aware about of STI/RTIs other than HIV. Surveys were conducted during 2006-07 in six states of India by IIPS in collaboration with Population council, New Delhi and funded by Packard and Mac Arthur Foundations. The six states are: Jharkhand, Bihar, Rajasthan, Maharashtra, Andhra Pradesh and Tamil Nadu. See "Youth in India: Situation and Needs 2006-2007. Executive Summary” (2010), page 14 available at

http://www.popcouncil.org/pdfs/2010PGY_YouthInIndiaExecSumm.pdf
}

"HIV/AIDS and other Sexually Transmitted Diseases” should be removed from the present curriculum and included in the books of biology, not before the $10+2$ stage.

\section{Conclusion}

Adolescent health in India is still in an infant stage, and at risk of infanticide. If we want to deliver a comprehensive services package to our adolescents, then we have first to overcome a range of obstacles: traditional society, cultural restricttions - especially for girls—and the political-religious context. Only government action can put these hindrances aside.

But government actors are far from steering in the same direction. Improved coordination should be a first step. Coordination of policy processes amongst different departments and different ministries-especially the need to identify a lead agency which has the mandate and power to coordinate-is the key to any government policy. In ARSH, shattered by many and buried in complexity, coordination and steering becomes imperative. However, this can only be a first step. From 'health for the adolescents' to 'health with the adolescents', there is still a long way to go.

\section{REFERENCES}

Anandhi, S. (2007). Sex education conundrum. Economic and Political Weekly, 42, pp. 3367-3369.

GoI (2001). Census of India, registrar general of India, Government of India.

Gupta, S. D. (2003). Adolescent and youth reproductive health in India - Status, issues, policies and programs, POLICY Project.

IIPS (International Institute for Population Sciences), \& ORC Macro (2007). National Family Health Survey, 2005-06 (NFHS-3). Mumbai.

Jejeebhoy, S. J. (1998). Adolescent sexual and reproductive behaviour: A review of the evidence from India. Social Science \& Medicine, 46, pp. 1275-1290. doi:10.1016/S0277-9536(97)10056-9

MAMTA (2001). Adolescent health and development in India: An action approach. New Delhi: MAMTA Health Institute for Mother and Child.

MoHFW (2005a). RCH phase II: National program implementation plan. New Delhi: Ministry of Health \& Family Welfare, Government of India,

MoHFW (2005b). National rural health mission, mission documentMeeting people's health needs in rural areas framework for implementation. New Delhi: Ministry of Health and Family Welfare, Government of India, URL (last checked 7 October 2012). http://mohfw.nic.in/NRHM.htm

MoHFW (2006). Implementation guide in RCH II adolescent reproductive sexual health strategy for state and district programme managers. New Delhi: Ministry of Health and Family Welfare, GoI.

MoHFW (2009). State Annual Programme Implementation Plans under NRHM. URL (last checked 20 September 2012). http://www.mohfw.nic.in/NRHM/Annual_Plan_Final.htm

MoYaS (2008). Annual report 2007-08 ministry of youth affairs and sports. URL (lase checked 27 January 2012). http://yas.nic.in/index1.asp?langid=1\&linkid=51

Pande, R. (2006). Improving the reproductive health of married and unmarried youth in India. New Delhi: ICWR.

Planning Commission (2007). Draft final report of the working group on youth affairs and adolescents' development for formulation of 11th Five Year Plan (2007-12), GoI. URL (lase checked 25 January 2011).

http://planningcommission.gov.in/aboutus/committee/11strindx.htm

Population Council and IIPS (2007). "Youth in India: Situation and needs 2006-2007. Executive Summary. URL (lase checked 22 September 2012).

http://www.popcouncil.org/pdfs/2010PGY_YouthInIndiaExecSumm. 
pdf

Rajya Sabha (2009). Rajya Sabha Committee on petitions, hundred and thirty-fifth report on petition praying for national debate and evolving consensus on the implementation of the policy for introduction of sex education in the schools and holding back its introduction until then. New Delhi: Rajya Sabha Secretariat.

RFSU (2004). Breaking through: A guide to sexual and reproductive health and rights, ICPD-the foundation for the millennium development goals. Stockholm: The Swedish Association for Sexuality Education (RFSU).

UN (United Nations) (2008). UN mapping: World Bank.
http://www.un.org.in/Jinit/wb.pdf

UNI (2009). Centre rejects recommendation for reducing marriage age of boys, 24th Jan 2009, United News of India. URL (last checked 27 January 2009).

http://news.webindia123.com/news/Articles/India/20090124/116047 7.html

UNICEF (United Nations Children's Fund) (2008). The state of the world's children 2009. UNICEF, New York. URL (last checked 22 January 2012).

www.unicef.org/publications/index_47127.html 